\title{
A BRIEF HISTORY OF MYASTHENIA GRAVIS AND THYMECTOMY
}

\author{
Bharath $V^{1}$
}

${ }^{1}$ All India Institute of Medical Sciences

January 25, 2021

\begin{abstract}
Myasthenia gravis (MG) is a rare autoimmune neuromuscular disorder. Though MG was diagnosed four centuries ago, its rational management started in 1930s. In the present era, MG is managed by both medical means and surgical techniques. In this article, the concise history of MG and its management is being described.
\end{abstract}

\section{A BRIEF HISTORY OF MYASTHENIA GRAVIS AND THYMECTOMY}

V, Bharath ${ }^{1}$

1 - Department of Cardiothoracic and Vascular Surgery, All India Institute of Medical Sciences, New Delhi, India

\section{ABSTRACT}

Myasthenia gravis (MG) is a rare autoimmune neuromuscular disorder. Though MG was diagnosed four centuries ago, its rational management started in 1930s. In the present era, MG is managed by both medical means and surgical techniques. In this article, the concise history of MG and its management is being described.

Keywords: Myasthenia gravis, thymectomy, VATS

History of Myasthenia gravis

Myasthenia gravis (MG) is a neuromuscular disorder characterized by weakness and fatigability of skeletal muscles ${ }^{1}$.

The first described case of MG is likely that of the Native American Chief Opechancanough, who died in 1664, as reported by Virginian chroniclers: "The excessive fatigue he encountered wrecked his constitution; his flesh became macerated; his sinews lost their tone and elasticity; and his eyelids were so heavy that he could not see unless they were lifted up by his attendants . . . he was unable to walk; but his spirit rising above the ruins of his body directed from the litter on which he was carried by his Indians" 2 . In 1672, the English physician Thomas Willis described a patient with the "fatigable weakness" of limbs and bulbar muscles characteristic of Myasthenia gravis ${ }^{3}$.

In the late 1800 s, the first modern descriptions of patients with myasthenia symptoms were published, and the name "Myasthenia gravis" was coined by fusing the Greek terms for muscle and weakness to yield the noun "Myasthenia" and adding the Latin adjective "gravis", which means severe ${ }^{4}$.

\section{PATHOLOGY OF MG}


Thymus pathology is common in MG patients, as first noted in the late 1800s ${ }^{3}$. In 1959-1960, Simpson and Nastuck proposed independently that MG has an autoimmune etiology ${ }^{5,6}$. In 1973, Patrick and Lindstrom demonstrated that rabbits immunized with purified muscle-like AChR developed MG -like symptoms (experimental autoimmune Myasthenia gravis [EAMG] ${ }^{7}$.

\section{MEDICAL MANAGEMENT}

Attempts at rational treatments of MG began in the 1930s. A major step forward occurred in 1934 when Mary Walker realized that MG symptoms were similar to those of curare poisoning, which was treated with physostigmine, a cholinesterase inhibitor. She showed that physostigmine promptly improved myasthenia symptoms ${ }^{7}$, making anti-cholinesterase drugs a staple in MG management.

\section{SURGICAL TREATMENT - THYMECTOMY}

The exact mechanism by which thymectomy produces benefits in MG is uncertain. The possible mechanism includes: (1) thymectomy may eliminate source of continued antigen stimulation ;2) it may remove reservoir of B cells secreting acetylcholine -receptor antibody; and (3) in some way it may correct a disturbance in immune regulation ${ }^{8}$.

There are various studies which have shown remission of symptoms in non thymomatous and thymomatous MG following thymectomy. The first observation that thymectomy influenced course of myasthenia gravis was made by Sauerbruch, who in 1911 performed thymectomy on a girl with hyperthyroidism and MG ${ }^{9,10}$.

In 1939, Alfred Blalock and associates reported relief of symptoms following resection of thymus in a 26 year old woman with myasthenia gravis and a thymic cyst through median sternotomy ${ }^{11,12}$. They reported that - "Complete removal of all thymus tissue offers the best chance of altering the course of disease" 13 . He also noticed that the results of thymectomy were better in patient with thymoma ${ }^{14}$. Since then studies have shown that thymectomy may increase the probability of a patient going into disease remission ${ }^{13}$.

Initially thymectomy, with either cervical or sternal approach, entailed removal of thymus gland only. In 1988 Jaretzki and colleagues, and Masaoka and Monden documented the presence of nests of thymic tissue outside thymic capsule in mediastinal and cervical fat in autopsy studies of patients with $\mathrm{MG}^{15-17}$. With this knowledge, the extent of surgery was extended to include all the fibrofatty tissue (including thymus) between the phrenic nerves and from thyroid gland upto the diaphragm. These were inaccessible through cervical incision. Studies by Masaoka and Monden showed more radical removal of thymus along with mediastinal fibrofatty tissue had higher remission rate ${ }^{17}$. Hence extended thymectomy through trans-sternal route became the more accepted approach. Subsequently some authors advocated maximal thymectomy using a combination of trans-sternal and cervical approach as the benchmark against which all other surgical techniques should be evaluated ${ }^{18}$.

With the advent of minimal access surgery, attempts have been made to perform thymectomy through Video Assisted Thoracoscopic approach (VATS). The thoracoscopic approach to thymectomy was first reported almost simultaneously by Sugarbaker from Boston ${ }^{19}$ and the Belgium group in $1993{ }^{20}$. Minimal invasive approaches have been reported to achieve similar extent of thymus removal as described for extended thymectomy by trans-sternal route ${ }^{21}$ with the benefit of improved surgical morbidity and shortened hospital stay and comparable remission rates ${ }^{22-24}$.

Conflict of Interest: None

Funding: None

IRB approval: N/A

Consent statement: N/A

Clinical trial registration: N/A

REFERENCES 
1. Dan L. Longo, Dennis L. Kasper, J. Larry Jameson, Anthony S. Fauci, Stephen L. Hauser, Joseph Loscalzo. Harrison's Principles of Internal Medicine. 18th edition. United States of America: The McGraw-Hill Companies;2012, Chapter 386.

2. Marsteller, H.B. The first American case of myasthenia gravis. Arch. Neurol. 1988;45:185-7.

3. Pascuzzi, R.M. The history of myasthenia gravis. Neurol. Clin. 1994;12:231-42.

4. Keesey, J.C. "Crisis" in myasthenia gravis: an historical perspective. Muscle Nerve. 2002;26:1-3.

5. Nastuk, W.L., Strauss, A.J., and Osserman, K.E. 1959. Search for a neuromuscular blocking agent in the blood of patients with myasthenia gravis. Am. J. Med. 26:394-409.

6. Simpson, J.A. 1960. Myasthenia gravis, a new hypothesis. Scott. Med. J. 5:419-36.

7. Patrick, J., and Lindstrom, J. 1973. Autoimmune response to acetylcholine receptor. Science. 180:8712.

8. Blalock A, Harvey AM, Ford FF, Lilienthal J Jr. The treatment of myasthenia gravis by removal of the thymus gland. Br J Surg 1946; 32: 201-14.

9. Sauerbruch H, Schumacher CB, Roth J. Thymektomie bei einem Fall von Morbus Basedowi mit Myasthenie. Mitteil Grenzgeb Med Chir. 1913;25:746.

10. Sanjay G. Khicha et al. Extended Transcervical Thymectomy in the treatment of myasthenia gravis. Annals of the New York Academy of Sciences. 2008;1132:336-43.

11. Blalock A, Mason MF, Morgan HJ, et al. Myasthenia gravis and tumors of the thymic region. Ann Surg 1939;110:544.

12. Kirschner PA. Alfred Blalock and thymectomy for myasthenia gravis. Ann Thorac Surg 1987;43:348.

13. Blalock A, et al. The treatment of myasthenia gravis by removal of the thymus gland. JAMA 1941;117:1529.

14. Keynes G. et al. The results of Thymectomy in Myasthenia Gravis. Br Med J.1949;2(4628):611-6.

15. Jaretzki A III, Penn AS, Younger DS, et al. "Maximal" thymectomy for myasthenia gravis. Results. JThorac Cardiovasc Surg 1988;95(5):747-57.

16. Jaretzki AIII, WolffM. "Maximal" thymectomy for myasthenia gravis. Surgical anatomy and operative technique. JThorac Cardiovasc Surg 1988;96(5):711-6.

17. Masaoka A, Monden Y. Comparison of the results of transsternal simple, transcervical simple and extended thymectomy. Ann N Y Acad Sci 1981;377:755.

18. Cooper J, Jaretzki III A, Mulder D G, Papatestas A S. Symposium: thymectomy for myasthenia gravis. Contemp Surg. 1989;34:65-86.

19. Sugarbaker DJ. Thoracoscopy in the management of anterior mediastinal masses. Ann Thorac Surg 1993;56:653- 6 .

20. Coosemans W, Lerut TE, Van Raemdonck DE. Thoracoscopic surgery: the Belgian experience. Ann Thorac Surg 1993;56:721-30.

21. Zahid I, Sharif S, Routledge T, Scarci M. Video-assisted thoracoscopic surgery or transsternal thymectomy in the treatment of myasthenia gravis? Interactive Cardiovascular and Thoracic Surgery 2011;12:40-6.

22. Toker A, ErogVlu O, Ziyade S, Tanju S, Senturk M, Dilege S, et al. Comparison of early postoperative results of thymectomy: partial sternotomy vs. videothoracoscopy. Thorac Cardiovasc Surg 2005;53:110-3.

23. Mineo TC, Pompeo E, Lerut TE, Barnardi G, Coosemans W, Nofroni I. Thoracoscopic thymectomy in autoimmune myasthenia: results of left sided approach. Ann Thorac Surg 2000;69:1537-41.

24. Savcenko M, Wendt GK, Prince SL, Mack MJ. Video assisted thymectomy for myasthenia gravis: an update of a single institution experience. Eur J Cardiothorac Surg 2002;22:978-83. 